altogether within the last two and a half years the $0^{\circ}$ line has been examined eleven times.

The preliminary examination of the repeated observations shows that there are important changes from month to month, particularly at the surface; but - and the discovery is a matter for great satisfaction-the changes in the deep water are not large enough to invalidate a qualitative picture of the water circulation drawn from observations made on only one or two occasions. It is hoped that a closer examination of the repeated observations will give reliable quantitative information, and that many problems - chiefly those connected with the speeds of the water and plankton movements-will be brought nearer solution.

The data and collections obtained, a valuable supplement to those of earlier voyages, have been brought to England, and the scientific staff are settling down to what it is hoped will be a very productive period.
The pressure of the scientific work on the fifth commission left little time for survey work, but charts have been prepared of the Balleny Islands, and of the antarctic coastline between the Greenwich meridian and $4 \frac{1}{2} \mathrm{E}$. Along this part of the coast there is a very narrow shelf, and in one place the ice. barrier was found to protrude beyond the 1,000 . fathom line. One bay, however, that was entered was found to end in a low ice-shelf 10 feet high with a sounding of 60 fathoms within a distunce of three cables; behind the bay snow-covered slopes rose gradually to $2,000 \mathrm{ft}$. The only exposed rock seen along the whole coastline was one snow-free boulder, and a small exposure at the foot of a shoulder.

The ship was commanded by Captain Hill, and Mr. Herdman was the senior scientific investigator on board. In addition to the Committee's own staff, Australian, New Zealand and South African scientific workers were carried for some parts of the com. mission.

\title{
Glass Technology at Sheffield
}

\section{New Buildings}

$\mathrm{T}$ HE Department of Glass Technology in the University of Sheffield came into being as a result of a scientific advisory committee set up by the University of Sheffield in 1914. The Department was founded in June 1915 and existed by courtesy in various rooms in the University buildings. A small building to deal with experimental work was erected and occupied without any formality early in 1917 , but growth and the need for returning borrowed accommodation to its rightful owners on the conclusion of the Great War compelled a move to other premises some distance from the University buildings in 1921. It was always felt that such a move could only be temporary, but not until 1935 was a suitable site found to house the Department in a worthy manner. This was acquired in 1936, the twenty-first anniversary year of the Department, and the appeal for funds called forth a most gratifying response. In addition to the subscriptions of more than $£ 37,000$ to the Glass Delegacy's fund, the Society of Glass Technology has contributed $£ 2,600$ towards the cost of the lecture theatre and adjacent rooms, and old students and staff have furnished the professor's room. The Frank Wood Library also was the subject of a special fund of some $£ 1,150$.

On Monday, June 12, the new buildings were formally opened by the Right Hon. Lord Riverdale of Sheffield, chairman of the Advisory Council for Scientific and Industrial Research, after dedication by the Right Rev. the Lord Bishop of Sheffield.

In his remarks, Lord Riverdale emphasized that one of the prime needs of the world to-day is confidence. Such confidence in the Glass Department has been felt by the industry that these new buildings are the result. What began as a local movement is now not only national but also international, for the Society of Glass Technology draws its members from all over the world and works in harmony with other similar bodies abroad.

The actual opening ceremony consisted of the drawing apart of curtains woven from glass silk hung before the main doorway. Mr. Geoffrey Pilkington then unveiled a tablet in the porch commemorating the opening, after which a degree congregation was held in the Museum for the purpose of conferring the degree of LL.D. on Mr. S. B. Bagely, the chairman of the Glass Delegacy, and of Ph.D. on Mr. B. P. Dudding, who as president of the Society of Glass Technology that year launched the Society's Elmfield Fund. The vice-chancellor, Dr. Irvine Masson, said that the building is a monument to the good relations between the University and the glass industry. Its products would be two-new knowledge and scientifically trained men.

The president of the Society of Glass Technology, Dr. C. J. Peddle, next unveiled in the lecture theatre a tablet bearing the names of the donors to the Society's fund, and the ceremonies were pleasantly concluded by the presentation to Lord and Lady Riverdale of a glass rose bowl by Mrs. W. E. S. Turner, and a speech of thanks by Prof. Turner, to whom many tributes were paid during the day's proceedings.

Afterwards the Department was inspected by the guests. It is situated in two and three quarter acres of attractive grounds overlooking on either side small reservoirs and is about six minutes' walk from the main University buildings. The original stonebuilt house has been retained to form an adminis. trative section. It contains on the ground floor an entrance hall with a pair of stained glass windows by Mr. S. M. Scott depicting glass makers at work and will house later a large tablet with illustrations of great achievements by English glass makers during three centuries and bearing the names of donors to the Glass Delegacy's Fund. In the porch is a glass-fronted niche containing a glass casket which holds historic records. Opening off the entrance hall are the conference room, the professor's room and the visitor's room. On the first floor is the Frank Wood Library, containing a stained glass window in memory of Mr. Frank Wood, a librarian's room, 
records room and ladies' rest rooms, whilst the second floor contains a small classroom and various store rooms.

The new building runs on from the house to give a total frontage of $151 \mathrm{ft} .6 \mathrm{in}$., with a mean depth of $50 \mathrm{ft}$. It consists of Section A, separated by a second entrance hall from Section B. In addition, Section $\mathrm{C}$ runs off to form the limb of a letter $\mathrm{L}$ and contains the heavier practical equipment. Section A contains on the ground floor a central corridor opening into rooms on either side. These comprise the following : general office, refectory and kitchen, in which good use is made of glass for tiling and table tops, mechanics' shop, drawing office, and laboratories for the study of optical radiation and $\mathrm{X}$-ray, mechanical and thermal properties, with a small dark room. On the same floor, Section $B$ contains students' cloakrooms, a general physical and a high-temperature laboratory, and store rooms for apparatus and materials. On the first floor, the whole of Section A is taken up by a museum $60 \mathrm{ft}$. long and $31 \mathrm{ft}$. wide on one side, whilst the remaining space comprises a small lecture room, museum keeper's store, and a decorative processes laboratory. Outside the museum in Section B is the landing, with office, leading to the lecture theatre and preparation room. The theatre seats approximately one hundred and has a projection gallery, dimming device, and the usual services. On the second floor are the two laboratories, students and research, for work of a chemical nature, and two smaller rooms which are equipped for special branches of research. There are also an office and store rooms and the projection room on this floor. A lift connects all floors with the basement, where the following are located: meter room and pipe duct, boiler room, battery room, dynamo room, and various store rooms.

Section C, only half of which is at present erected, is to have a length of $75 \mathrm{ft}$. It now consists of three rooms, one of which is built over an archway and is devoted to raw materials and mixing, whilst of the other two, $50 \mathrm{ft}$. by $36 \mathrm{ft}$., that on the ground floor is used for the storage, preparation and testing of refractories, two small laboratories being partitioned off for the latter purpose. The remaining room on the first floor is given over to glass melting and is equipped with a variety of furnaces, gas and electrically heated. Provision has been made for the building of large furnaces, and an adjustable stage has been built below an opening in the floor to accommodate regenerator or recuperator structures without taking up too much of the space in the refractories section below.

Throughout the building glass has been used as much as possible and Vitrolite, glass bricks, Thermolux and armour-plate glass, together with glass silk insulation have been effectively employed. Special mention may be made of the large glass dome over the stairway, the glass panels in the latter, the various stained glass windows, and the window to be erected in the museum depicting "Glassmaking through the Centuries".

\section{The Royal Society and the Kaiser Wilhelm Gesellschaft \\ Exchange of Visits}

$I^{N}$ $N$ the autumn of 1938 , following a suggestion of the president of the Kaiser Wilhelm Gesellschaft, arrangements were made by the president of the Royal Society of London, Sir William Bragg, and representatives of the Kaiser Wilhelm Gesellschaft, for an exchange of visits between these two bodies. The Kaiser Wilhelm Gesellschaft, founded in $191 \mathrm{I}$ at the suggestion of the Kaiser Wilhelm II, has as its aim the encouragement of the natural and human sciences, primarily by establishing and maintaining research institutes for natural science in Germany.

This exchange of visits was welcomed by the Royal Society, which, since its foundation in 1662 , has always sought to maintain, irrespective of race or politics, the liveliest interest in the work of men of science throughout the world. Consequently, arrangements were made for two fellows of the Society, Prof. F. G. Donnan, emeritus professor of chemistry in the University of London, and Prof. A. J. Clark, professor of materia medica in the University of Edinburgh, to visit Germany in March ; at the express wish of the Kaiser Wilhelm Gesellschaft for a lecture on a non-scientific subject, Prof. Dover Wilson, the eminent Shakespearean scholar, was invited by the Royal Society to visit Berlin to lecture. The visits, which took place in March and April, were highly successful. The visitors were most hospitably entertained by their German colleagues and were afforded facilities for visiting laboratories and research institutes.
The Royal Society is entertaining during this month four German men of science. They are Freiherr von Verschuer, of the University of Frankfort-on-Main, Prof. R. Kuhn, of the Kaiser Wilhelm Institut für Medizinische Forschung, Heidelberg, Prof. F. Wever, of the Kaiser Wilhelm Institut für Fisensforschung Forschung, Düsseldorf, and Prof. Otto Hahn, of the Kaiser Wilhelm Institut für Chemie, Berlin-Dahlem. Freiherr von Verschuer and Prof. Kuhn delivered lectures before the Royal Society on June 8 and 9 respectively; Prof. Wever will speak at the Royal Society on June 22 at 4.30 on metallurgical research, and Prof. Hahn at the Royal Institution on June 23 at 2.30 on the fission of uranium nuclei by neutrons.

\section{RESEARCH IN TWINS}

The first exchange lecture between the Kaiser Wilhelm Gesellschaft and the Royal Society was given on June 8 by Freiherr von Verschuer, professor of human genetics and eugenics at the University of Frankfort-on-Main. This institution has devoted itself especially to the study of twins and the subject of the lecture was twin research.

Prof. Verschuer pointed out that Galton in 1875 was the first to recognize the importance of the study of inheritance in twins, distinguishing between monozygotic or identical, and dizygotic or fraternal, twins. The twin method dissociates the parts played 